\title{
Symptom remission and functional outcome in an Egyptian sample of patients with schizophrenia
}

\author{
Reem El Ghamry, Ahmed Saad, Amira Nassieb Elbatrawy, Ghada A. M. Hassan, Eman S. Rabie and \\ Mohamed Youssef Mohamed* (i)
}

\begin{abstract}
Background: The ultimate treatment goal of schizophrenia is regaining patients' pre-morbid function.

Results: Ninety-three outpatients with schizophrenia, diagnosed according to the criteria of Diagnostic and Statistical Manual of Mental Disorders - fourth edition (DSM-IV), were recruited, of whom 35 patients (37.6\%) had achieved the remission severity criteria, whereas 58 patients (62.4\%) failed to fulfill the criteria for remission. The functional aspects were examined by the Global Assessment of Functioning scale (GAF) and the Social Functioning Questionnaire (SFQ). Predictors of outcome were examined by applying binary logistic regression analysis. Patients who fulfilled those specific criteria for remission showed a favorable outcome in the assessed areas, regarding GAF and social functioning in society. Lack of judgment or insight item of PANSS showed significantly good functional outcomes.

Conclusion: The results suggest that the remission concept has important implications for the treatment of schizophrenia. Remission seems to be associated with better functional capabilities. However, this does not necessarily mean that remitted patients have "adequate"functioning, especially regarding the social skills domain.
\end{abstract}

Keywords: Remission, Schizophrenia, Egypt, Outcome, PANSS

\section{Background}

Along with the development of new psychological and pharmacological treatment strategies for schizophrenia, the need for a consensual definition of remission for patients with schizophrenia became louder [1].

For a long time, there has been no specific definition of schizophrenia remission. That is why there has been scarce of comparison studies measuring this outcome [2]. A trial to put specific criteria for defining remission in schizophrenia by a group of researchers called Remission in Schizophrenia Working Group (RSWG) in 2005, in an attempt to make a well-defined outcome measure for all

\footnotetext{
*Correspondence: mohamed_youssef@med.asu.edu.eg Okasha's Institute of Psychiatry, A WPA Collaborating Center for Training and Research in Psychiatry, Ain Shams University, P.O. Box: 11657 Abbasseyia, Ramses Street Extension, Dair Al-Malak, Cairo, Egypt
}

researchers that become useful in the long-term management of the disease [3, 4].

These criteria consist of two categories: a symptombased criterion and a time-based criterion. Concerning the symptom based criteria, they have agreed that a score of 3 per item is necessary to be defined as remitted. They include eight items in the PANSS which are unusual thought content, delusions, conceptual disorganization, hallucinatory behavior, mannerisms, social withdrawal, blunted affect, and the lack of spontaneity [3].

On the other hand, time-based criteria require a duration of at least 6 months for remission to be described as persistent. However, these criteria and its relation to the outcome are still not valid till now and require further research [2].

Remission criteria appear sustainable for most patients and are found to be associated with a better 
functional outcome, symptomatic improvement, better attitude about insight and drugs, and a better quality of life (QoL) and cognitive performance [5].

The lack of a specific definition for a functional remission and QOL improvement remains a problem, so that the predictive validity of this outcome measure cannot be adequately studied [6]. Different studies reported that symptomatic remission, as defined by Andreasen et al., is significantly related to better social and daily functioning but not necessarily accompanied by functional remission in all domains $[1,7]$.

Bodén et al. applied the remission criteria to some patients with first-episode schizophrenia and followed them up for 5 years to study its association with the functional outcome [8]. They found that symptomatic remission was significantly associated with life satisfaction and better functional status. Bobes et al. performed a multicenter study recruiting 1010 patients with schizophrenia spectrum disorders and studied the remission criteria and their functional status through the global assessment of functioning scale (GAF) in Spain [9].

They found that despite $45 \%$ of patients were in the stage of symptomatic remission, only $10.2 \%$ of them had better functional status. Patients who achieved the criteria of remission had a higher functioning level in several areas of life. They were better educated, were more often occupied, possessed more established social networks, were liable to be living under family-like conditions, and required fewer healthcare resources. Most patients were in both functional and symptomatic remission; however, only a few patients had incomplete functional remission despite being symptomatically remitted [1].

We hypothesized that patients meeting the remission criteria would be functioning significantly better than patients with no symptom remission. So, we performed this study in order to investigate that hypothesis.

\section{Methods \\ Design and procedures}

This study was a cross-sectional observational study done between June 2016 and September 2017. It was carried out at outpatient clinics of Okasha Institute of Psychiatry, Ain Shams University Hospital. Patients who were previously admitted at the institute and discharged at least 1 year ago were recruited through the researcher at the outpatient settings, at which they received pharmacological treatment. All participation was on a free volunteer basis. Patients accepting to take part in the study underwent investigations and interviews that were not normally apart of their treatment interviews. The average time for each interview was $2 \mathrm{~h}$.

\section{Participants}

A convenient sample of a hundred patients was recruited from patients attending general adult psychiatry clinics at the Institute of Psychiatry, Ain Shams University Hospitals, who were discharged at least 1 year ago. Seven patients were excluded due to refusal to continue in the study. Ninety-three patients were diagnosed to have schizophrenia according to DSM-IV diagnostic criteria. Patients who met the inclusion criteria were recruited. Their age was between 18 and 50 years old. Patients diagnosed with substance-induced psychosis, psychosis secondary to a general medical condition, schizoaffective disorders, or delusional disorder were excluded. Also, any neurological condition that could affect course or diagnosis (epilepsy, cerebrovascular strokes, multiple sclerosis) or comorbidity with an intellectual disability or ASD (autism spectrum disorder) was excluded. Informed written consent was obtained from all participants before inclusion.

\section{Measures}

Full medical and surgical history was obtained from all participants. Mental status examination was done in addition to full medical examination especially neurological one was done for all included patients.

We used the Arabic version of the structured clinical interview for DSM-IV axis I diagnosis (SCID-I) [10, 11]. It was applied to the subjects to establish the diagnosis of schizophrenia and to exclude other axis I diagnoses. To measure the severity of symptoms of schizophrenia, we used positive and negative syndrome scale (PANSS). This scale consists of 30 items, divided into three distinct groups of symptoms: positive, negative, and general symptoms [12].

\section{Outcome measures}

Symptom remission was our primary outcome. According to (PANSS) instrument, full remission was defined as the achievement of remission (score 3 or less) on at least eight symptoms from PANSS. For functional aspects, we used the Global Assessment Functioning scale (GAF).

The Global Assessment Functioning scale (GAF) is one used for measuring the overall severity of psychiatric diseases. It is used to assess the social, psychological, and occupational aspects of adults, functioning by mental health clinicians and physicians through a scale of 100. It was first described through the DSM-IV-TR [13].

\section{Social functioning questionnaire (SFQ)}

The Social Functioning Questionnaire (SFQ) is a rating scale for a detailed assessment of the individual level of adaptive functioning, for both rehabilitation and 
research purposes. SFQ is a 41-item questionnaire. It is divided into 5 sections; each section is composed of 8 items (except for the first section, which is composed of 9 items).

These 5 sections should be completed for each person, and they assess the following dimensions: selfcare, domestic skills, community skills, social skills, and responsibility [14]. The items of the questionnaire are scored using a 4-point rating Likert scale. A rating of 1 indicates poor ability, and a rating of 4 indicates high ability. Then, a mean score is given both for overall and component skill levels. If there is a missing value for any item, the item is invalid for analysis, and " 9 " is written within the value. In this study, we used an Arabic version of this questionnaire which was developed through-translation and back-translation process by Hussein et al. [15].

\section{Operational definition}

Functional remission was created and defined as the following: (1) a GAF score of $\geq 61$ points according to traditional definitions from the literature [16-18], (2) a mean score of a global measure of social functioning $\geq 3.2$ indicating high functioning, and (3) independent living (paid employment/doing housework independently).

Symptomatic remission was defined according to Andreasen remission criteria. The current sample was divided into two groups according to their outcome. Good outcome was considered when both symptomatic and functional remissions are achieved. Whereas meeting only symptomatic or functional remission or failure to meet both was considered as a poor outcome.

\section{Statistical analyses}

Statistical analyses were done using the Statistical Package for Social Sciences [19]. The Kolmogorov-Smirnov test was performed to test the normality of numerical data distribution. Normally distributed numerical data were presented as mean and standard deviation. Qualitative data were presented as numbers and percentages.

Normally distributed numerical data were compared by the independent-samples Student $t$ test. For multiple intergroup comparisons, one-way ANOVA was used, with the application of the Scheffe test post hoc whenever a statistically significant difference was detected with one-way analysis of variance. The Pearson chi-square test was used for comparison of groups as regard differences in categorical data. Fisher's exact test was used instead if greater than $25 \%$ of the cells had an expected count of smaller than or equal to 5 .

Binary logistic regression was used to test the relation between dependent and independent variables after adjustment of the confounding factors. $P$ value less than 0.05 was considered statistically significant.

\section{Results}

Ninety-three patients were enrolled in the study (67 males and 26 females), 83 (89\%) had received BST, and all of them on pharmacological treatment.

Thirty-five patients (37.6\%) had achieved remission severity criteria, whereas 58 patients $(62.4 \%)$ failed to fulfill the criteria for remission. The socio-demographic characteristics and the clinical findings of the study participants are described in Table 1. Symptomatic remitters had a more frequent employment status compared to non-remitters and a shorter duration of untreated psychosis.

\section{Functional aspects in symptomatic remitters and non-remitters}

The current study found a highly significant difference in the global measure of social functioning between symptomatic remitters and non-remitters. Yet, to be noted that $(80 \%)$ of the symptomatic remitters showed high functioning as a global measure of social functioning; however, only $17 \%$ had high functioning in social skills item, indicating impairment of social skills even in the symptomatic remitters with high global functioning as shown in Table 2.

\section{Functional remission}

Regarding functional remission as defined previously in the current study, current results revealed that 25 (71.4\%) of symptomatic remitters achieved functional remission compared to only 7 (12\%) in non-remitters with a highly statistically significant difference as shown in Table 3.

\section{The outcome of the study sample}

The current sample was divided into two groups according to their outcome. Good outcome was defined by achieving both symptomatic and functional remission. Whereas meeting only symptomatic or functional remission or failure to meet both was considered as a poor outcome.

Current results revealed that 25 (27\%) of the study sample had a good outcome compared to 68 (73\%) who had a poor outcome (Table 4).

\section{Predictors of a good outcome}

Predictors of a good outcome were examined by applying binary logistic regression. Variables entered according to the statistical significance of results were as follows: (1) lack of judgment or insight item of PANSS; (2) substance use; (3) previous suicidal attempts; (4) drug compliance. Results appeared to be that a lower score on lack of judgment or insight item of PANSS was a significant predictor of a good outcome. On the other hand, substance use, previous suicidal attempts, and drug compliance were 
Table 1 Socio-demographic characteristics and clinical findings of both groups

\begin{tabular}{|c|c|c|c|c|c|c|}
\hline & & \multicolumn{2}{|c|}{$\begin{array}{l}\text { Symptomatic remitters }(n= \\
35)\end{array}$} & \multicolumn{2}{|c|}{$\begin{array}{l}\text { Symptomatic non-remitters } \\
(n=58)\end{array}$} & \multirow[t]{2}{*}{$P$ value } \\
\hline & & Mean & SD & Mean & SD & \\
\hline \multicolumn{2}{|l|}{ Age } & 35.9 & 7.97 & 35.4 & 9.4 & 0.8 \\
\hline \multicolumn{2}{|l|}{ Age of illness onset } & 24.6 & 5.4 & 23.6 & 5.9 & 0.4 \\
\hline \multicolumn{2}{|l|}{ Duration of illness } & 11.3 & 6.2 & 11.9 & 7.4 & 0.7 \\
\hline \multicolumn{2}{|l|}{ Total PANSS } & 44.5 & 7.3 & 72.5 & 20.4 & $<0.001^{* *}$ \\
\hline \multicolumn{2}{|l|}{ PANSS total positive } & 9.2 & 1.8 & 17.9 & 7.1 & $<0.001^{* *}$ \\
\hline \multicolumn{2}{|l|}{ PANSS total negative } & 11.7 & 2.6 & 20.6 & 7.2 & $<0.001^{* *}$ \\
\hline \multicolumn{2}{|l|}{ Composite } & 2.0 & 0.5 & 1.7 & 0.5 & $0.01 *$ \\
\hline \multicolumn{2}{|l|}{ Somatic concern G1 } & 1.2 & 0.4 & 1.3 & 0.7 & 0.2 \\
\hline \multicolumn{2}{|l|}{ Anxiety G2 } & 1.7 & 0.96 & 1.7 & 1.0 & 0.8 \\
\hline \multicolumn{2}{|l|}{ Guilt feeling G3 } & 1.3 & 0.6 & 1.3 & 0.7 & 0.8 \\
\hline \multicolumn{2}{|l|}{ Tension G4 } & 1.7 & 0.9 & 1.6 & 0.7 & 0.9 \\
\hline \multicolumn{2}{|l|}{ Depression G6 } & 1.6 & 0.8 & 1.6 & 1.1 & 0.99 \\
\hline \multicolumn{2}{|l|}{ Lack of judgment } & 2.1 & 0.6 & 3.9 & 1.3 & $<0.001^{* *}$ \\
\hline \multirow[t]{2}{*}{ Gender } & Male & 23 & 34 & 44 & 66 & 0.29 \\
\hline & Female & 12 & 46 & 14 & 54 & \\
\hline \multirow[t]{5}{*}{ Education } & Illiterate & 5 & 14 & 9 & 15 & 0.2 \\
\hline & Primary school & 7 & 20 & 10 & 17 & \\
\hline & Technical & 14 & 40 & 20 & 35 & \\
\hline & Secondary & 4 & 11 & 1 & 2 & \\
\hline & University & 5 & 14 & 18 & 31 & \\
\hline \multirow[t]{2}{*}{ Residence } & Urban & 28 & 80 & 38 & 65 & 0.1 \\
\hline & Rural & 7 & 20 & 20 & 35 & \\
\hline \multirow[t]{3}{*}{ Marital status } & Single & 17 & 49 & 36 & 62 & 0.4 \\
\hline & Married & 14 & 40 & 16 & 28 & \\
\hline & Sep./div. & 4 & 11 & 6 & 10 & \\
\hline \multirow[t]{4}{*}{ Occupation } & Employed & 17 & 48.5 & 14 & 24 & $<0.001^{* *}$ \\
\hline & Unemployed & 7 & 20 & 37 & 64 & \\
\hline & Student & 1 & 3 & 2 & 3.4 & \\
\hline & Housewife & 10 & 28.5 & 5 & 8.5 & \\
\hline \multirow[t]{2}{*}{ Substance use } & Yes & 8 & 23 & 20 & 35 & 0.2 \\
\hline & No & 27 & 77 & 38 & 65 & \\
\hline \multirow[t]{2}{*}{ DUP } & Less than 3 months & 20 & 57 & 19 & 33 & $0.02^{*}$ \\
\hline & More than 3 months & 15 & 43 & 39 & 67 & \\
\hline \multirow[t]{2}{*}{ FH PI } & Yes & 15 & 43 & 19 & 33 & 0.3 \\
\hline & No & 20 & 57 & 39 & 67 & \\
\hline
\end{tabular}

N Number, SD Standard deviation, DUP Duration of untreated psychosis, FHPI Family history of psychiatric illness

not considered as significant predictors of a good outcome with $p$ value equals $0.1,0.4$, and 0.5 respectively (Table 5).

\section{Discussion}

Remission is considered a major issue in schizophrenia outcome. For a long time, schizophrenia was thought to be an inevitable disease with no remission end point so that it was described as dementia praecox by Kraepelin (REF). Recently, the course of schizophrenia was approved to be different among patients as many patients with schizophrenia experienced remission within longterm outcome studies performed recently.

Not only symptomatic remission but also functional remission were considered the goal of treatment in schizophrenia patients, so that, patients get a better quality of 
Table 2 Comparison between both groups as regard functional aspects in terms of GAF scale and SFQ

\begin{tabular}{|c|c|c|c|c|c|c|}
\hline & & \multicolumn{2}{|c|}{ Symptomatic remitters $(n=35)$} & \multicolumn{2}{|c|}{$\begin{array}{l}\text { Symptomatic non-remitters ( } n \\
=58)\end{array}$} & \multirow[t]{2}{*}{$P$ value } \\
\hline & & Mean & SD & Mean & SD & \\
\hline GAF & & 75 & 7.6 & 47 & 18 & $<0.001^{* *}$ \\
\hline \multirow[t]{4}{*}{ Global measure of SFQ } & High & 28 & 80 & 10 & 17 & $<0.001 * *$ \\
\hline & Moderate & 7 & 20 & 26 & 45 & \\
\hline & Low & 0 & 0 & 21 & 36 & \\
\hline & Poor & 0 & 0 & 1 & 1.7 & \\
\hline \multirow[t]{4}{*}{ Social skills of SFQ } & High & 6 & 17 & 1 & 1.7 & $<0.001^{* *}$ \\
\hline & Moderate & 26 & 74 & 19 & 32.8 & \\
\hline & Low & 3 & 9 & 27 & 46.6 & \\
\hline & Poor & 0 & 0 & 11 & 19 & \\
\hline
\end{tabular}

SD Standard deviation, GAF Global assessment of functioning, SFQ Social Functioning Questionnaire

*Statistical significance

**High statistical significance

Table 3 Comparison between symptomatic remitters and nonremitters as regard functional remission

\begin{tabular}{|c|c|c|c|c|c|}
\hline & \multicolumn{2}{|c|}{$\begin{array}{l}\text { Symptomatic } \\
\text { remitters }(n=35)\end{array}$} & \multicolumn{2}{|c|}{$\begin{array}{l}\text { Symptomatic } \\
\text { non-remitters ( } n \\
=58 \text { ) }\end{array}$} & \multirow[t]{2}{*}{$P$ value } \\
\hline & $N$ & $\%$ & $N$ & $\%$ & \\
\hline $\begin{array}{l}\text { Functional remis- } \\
\text { sion }\end{array}$ & 25 & 71.4 & 7 & 12 & $<0.001^{* *}$ \\
\hline $\mathrm{GAF} \geq 61$ & 34 & 97 & 17 & 29 & $<0.001 * *$ \\
\hline $\begin{array}{l}\text { Global measure of } \\
S F Q \geq 3.2\end{array}$ & 28 & 80 & 10 & 17 & $<0.001^{* *}$ \\
\hline $\begin{array}{l}\text { Independent } \\
\text { living }\end{array}$ & 28 & 80 & 17 & 30 & $<0.001^{* *}$ \\
\hline
\end{tabular}

N Number, GAF Global assessment of functioning, SFQ Social Functioning Questionnaire

*Statistical significance

**High statistical significance

life and can be integrated again into their work places and communities, which reduces the social burden. There was a scarce of data regarding the functional and symptomatic remission in schizophrenia within the developing countries [20].

When studying the socio-demographic characteristics and clinical findings of the current study, it revealed that males out number females where the study included 67 (72\%) males and only 26 (28\%) females. This high gender difference could be justified that the incidence of schizophrenia was found to be higher in males than females as founded by Brown et al. [21]. Another possibility is that males are brought to medical services more often than females, who are more prone to stigma, as reported by Khan et al., whose findings revealed that women experience significantly greater levels of internalized stigma compared to men [22].

Several factors influence the outcome of schizophrenia. Marriage is one such important factor. Lane et al. reported that the percentage of schizophrenia patients getting married is much lower than the normal population or patients with other psychiatric disorders [23]. This comes in agreement with the current results, which revealed that most patients were single $(57 \%)$ versus (32\%) who were married and (11\%) who were divorced or separated.

It is worth mentioning that a highly statistically significant difference was found regarding the employment status where $60 \%$ of the good outcome group was employed compared to only $23.5 \%$ in the poor outcome group. These findings are in accordance with Madhivanan et al., who found that the remitted patients had significantly better employment status than unremitted patients [2]. Interestingly, the rate of unemployment in 2018 was $6.8 \%$ male and $21.4 \%$ female, while the marriage mean age was 30.6 years [24].

Furthermore, current study data revealed that $30 \%$ of the sample was on a regular substance, namely, tetrahydro-cannabinoid. Also, a significant difference was obtained between outcome groups as regard substance use, where $34(51 \%)$ of those in the poor outcome group used substances on regular basis compared to only 6 (24\%) in the good outcome group $(P=0.03)$. Drake et al. stated that individuals with schizophrenia are more liable to substance abuse disorders, while patients with concurrent schizophrenia and substance abuse are more susceptible to negative outcomes, including poor response to treatment, relapse, hospitalization, suicide, and a variety of psychosocial difficulties [25]. 
Table 4 Relation between socio-demographic characteristics and clinical findings of outcome groups

\begin{tabular}{|c|c|c|c|c|c|c|}
\hline & & \multicolumn{2}{|c|}{ Good outcome $(n=25)$} & \multicolumn{2}{|c|}{ Poor outcome $(n=68)$} & \multirow[t]{2}{*}{$P$ value } \\
\hline & & Mean & SD & Mean & SD & \\
\hline Age & & 37 & 7 & 35 & 9.4 & 0.8 \\
\hline \multirow[t]{2}{*}{ Gender } & Male & 15 & 60 & 52 & 76.5 & 0.26 \\
\hline & Female & 10 & 40 & 16 & 23.5 & \\
\hline \multirow[t]{3}{*}{ Marital status } & Single & 11 & 44 & 42 & 62 & $0.04 *$ \\
\hline & Married & 10 & 40 & 20 & 29.5 & \\
\hline & Divorced/separated & 4 & 16 & 6 & 8.5 & \\
\hline \multirow[t]{4}{*}{ Occupation } & Employed & 15 & 60 & 16 & 23.5 & $<0.001 * *$ \\
\hline & Unemployed & 1 & 4 & 43 & 63.2 & \\
\hline & Studying & 0 & 0 & 3 & 4.4 & \\
\hline & Housewife & 9 & 36 & 6 & 8.8 & \\
\hline \multirow[t]{2}{*}{ Substance use } & Yes & 6 & 24 & 34 & 51 & $0.03^{*}$ \\
\hline & No & 19 & 76 & 33 & 49 & \\
\hline \multirow[t]{2}{*}{ Medical comorbidity } & Yes & 6 & 24 & 13 & 19 & 0.6 \\
\hline & No & 19 & 76 & 55 & 81 & \\
\hline \multirow[t]{2}{*}{ FH of psychiatric illness } & Yes & 10 & 40 & 24 & 35 & 0.8 \\
\hline & No & 25 & 60 & 44 & 65 & \\
\hline \multirow[t]{2}{*}{ Suicidal attempt } & Yes & 4 & 16 & 27 & 40 & $0.04^{*}$ \\
\hline & No & 21 & 84 & 41 & 60 & \\
\hline \multirow[t]{2}{*}{ Drug compliance } & Good & 15 & 60 & 22 & 32 & $0.01^{*}$ \\
\hline & Bad & 10 & 40 & 46 & 68 & \\
\hline
\end{tabular}

N Number, SD Standard deviation, GAF Global assessment of functioning, SFQ Social Functioning Questionnaire, FH Family history, NS Non-statistical significance *S Statistical significance

**HS High statistical significance

Table 5 Lack of judgment and insight predictive value of good outcome in the study sample

\begin{tabular}{llll}
\hline & OR & 95\% C.I. of OR & Lower \\
\cline { 3 - 4 } & & Upper & 0.05 \\
\hline Lack of judgment and insight (G12) item of PANSS & 1.4 & 4.1 & $<0.001^{* *}$ \\
\hline $\begin{array}{l}\text { OR Odds ratio, C.I. Confidence interval } \\
\text { *HS High statistical significance }\end{array}$ & & & \\
\hline
\end{tabular}

In the current study, $37 \%$ of patients had a positive family history of psychiatric disorders in their first or second-degree relatives. This agrees with the results of an Egyptian study by Mansour et al., who found that $46.6 \%$ of patients diagnosed with schizophrenia had a known family history of psychiatric illness [26]. Also, Jaracz et al. reported that $40.6 \%$ had relatives who experienced psychiatric or mental disorders before [27]. These consistent findings emphasize the strength of the genetic component in the etiology of schizophrenia.

Duration of untreated psychosis (DUP) plays a major role in schizophrenia etiology because of its potential to be modified, raising the possibility of improving outcomes by shortening DUP [28, 29]. In the current study, we detected a significant association between DUP and symptom remission; where the shorter this duration was, the more symptomatic remission was achieved ( $p$ value 0.02). Simonsen et al. showed firm evidence for an association between DUP and outcome as shorter durations of untreated psychosis was associated with shorter time needed to remission, less aggravated positive symptoms, and better social functioning [30].

As regard symptom remission, it is worth mentioning that 35 patients $(37.6 \%)$ had achieved symptomatic remission, whereas 58 patients $(62.4 \%)$ failed to fulfill symptomatic remission. Similarly, Helldin et al. results 
showed that $38 \%$ had achieved remission severity criteria whereas $62 \%$ failed to fulfill the criteria for remission [31]. Also, Barak and Aizenberg reported that 37\% of patients gained symptomatic remission [32]. Moreover, Karow et al., as a part of The European Group of Functional Outcomes and Remission in Schizophrenia project (EGOFORS), found that the remission criteria by Andreasen were fulfilled by $44 \%$ of subjects [1].

The current study findings revealed that there was a close association between functional outcome and symptomatic remission as $71.4 \%$ of symptomatic remitters achieved functional remission compared to only $12 \%$ in non-remitters $(P<0.001)$. This indicates that symptomatic and functional statuses are closely related and that is why, they should be put together in the schizophrenia recovery definition. On the other hand, Karow et al. stated that symptomatic remission is associated with better social and daily functioning but not necessarily accompanied by functional remission in all domains [1].

While $80 \%$ of the symptomatic remitters showed high functioning as a global measure of social functioning, only $17 \%$ had high functioning in social skills item indicating affection of social skills domain even in the symptomatic remitters, with high global functioning. These findings come in concordance with Karow et al., who reported a significantly better level of functioning measured for remitted versus non-remitted patients [1]. However, patients with remission were still suffering inadequate functioning in certain aspects of daily life: in social relations (40\%), work (29\%), and daily life activities (17\%).

Regarding the global outcome, current results revealed that $25(27 \%)$ of the study sample had a good outcome, compared to $68(73 \%)$, who had a poor outcome. The present results agreed with Younes and Moselhy study in Iraq. They found that $23.4 \%$ were in the good outcome group, $23.8 \%$ were in the partial outcome group, yet $52.8 \%$ were in the poor outcome group regarding symptomatic and psychosocial functioning [33].

Moreover, a new model has been adopted by Lambert et al., called "best outcome." It integrates 3 main aspects: functional improvement, remission of core schizophrenia symptoms, and mental well-being which collectively improve the QOL in those patients. This best outcome was achieved in $21 \%$ of patients [34].

In the current study, no statistically significant difference was found regarding the age of illness onset and outcome. Similarly, Üçok et al. found no significant effect of age at onset of illness and outcome [35]. That may be explained by the fact that both groups in the current study had older age of onset $(23.6 \pm 5.9)$ and $(24.6 \pm 5.4)$ years respectively; however, the age of onset may have its impact in early-onset cases [36].

Meanwhile, there was a significant difference between the outcome groups in terms of drug compliance, as $68 \%$ of the poor outcome group had poor compliance compared to $40 \%$ in the good outcome group. Moreover, there was a highly statistically significant association between symptom severity assessed by total PANSS score and drug compliance $(p<0.001)$.

Higashi et al. systematically reviewed the factors affecting the compliance of schizophrenia patients to treatment and the results of non-compliance to the patient, healthcare system, and society and found that in patients with schizophrenia, severe symptoms were associated with worse adherence to treatment [37].

Regarding predictors of the outcome in the current study, we found that fewer lack of judgment or insight scores was significantly associated with a good outcome. On the other hand, substance use, previous suicidal attempts, and drug compliance were not considered as significant predictors of a good outcome $(p=0.1, p=$ $0.4, p=0.5$ ) respectively.

\section{Strength and limitations}

The current study is one among few studies in Egypt which investigated the clinical and functional outcome of patients with schizophrenia, yet there is also a need for evaluation of those subjects over a longitudinal period as the current study utilized a cross-sectional design, in contrast to some studies which have a prospective design. The cross-sectional study design enabled us to recruit a larger sample that might have been dropped from following up in prospective studies.

\section{Conclusions}

In conclusion, our results suggest that symptomatic recovery seems to be a good indicator of better functioning. However, this does not necessarily mean that remitted patients have an adequate functioning level, especially social skills domain. Also, current findings revealed that a significant proportion of patients showed either symptomatic or functional improvement; however, a smaller percentage of patients could achieve both symptomatic and functional remission criteria simultaneously.

\section{Abbreviations}

PANSS: Positive and Negative Syndrome Scale; DSM-IV: Diagnostic and Statistical Manual of Mental Disorders - fourth edition; GAF: Global Assessment of Functioning scale; SFQ: Social Functioning Questionnaire; RSWG: Remission in Schizophrenia Working Group; QoL: Quality of life; SCID-I: Structured clinical interview for DSM-IV axis I disorder; DUP: Duration of untreated psychosis; EGOFORS: European Group on Functional Outcomes and Remission in Schizophrenia project. 


\author{
Acknowledgements \\ Authors have no acknowledgement to make
}

\section{Authors' contributions}

RE helped in proposal writing, critically reviewed the manuscript, provided supervision and logistics, and supervised the workflow. AS participated in the design of the study, shared in the choice of the study tools, participated in the study conduction and planning, helped in statistical analysis, and modified the second draft of the manuscript. AE shared in the design of the study, participated in the choice of the study tools, supervised the study conduction and planning, and reviewed the manuscript. GH helped in proposal writing, supervised the workflow, provided supervision and logistics, and reviewed the manuscript. ER conceptualized, visualized, and designed the idea of the study; made the search of the literature; put a time plan for the progress of the study; and performed data collection, data cleaning, and the statistical analysis. MM helped in proposal writing; provided close supervision for data collection, statistical analysis, manuscript writing; provided supervision and logistics; and wrote the first manuscript draft. All authors have read and approved the manuscript.

\section{Funding}

Self-funded. We did not receive a financial assistance from any agencies in the commercial, public, or non-profit sectors.

\section{Availability of data and materials}

Not applicable.

\section{Declarations}

\section{Ethics approval and consent to participate}

Informed written consent was granted from all participants in the study before conducting the interviews. This study has been approved by the ethical and research committee of the faculty of medicine, Ain Shams University, under the number 297/2015 on 21 May 2015

\section{Consent for publication}

All participants were informed in writing and verbally about the study, and they granted their written consent before they were included in the study.

\section{Competing interests}

The authors declare that they have no competing interests.

Received: 15 June 2021 Accepted: 17 October 2021

Published online: 20 December 2021

\section{References}

1. Karow A, Moritz S, Lambert M, Schottle D, Naber D (2012) Remitted but still impaired? Symptomatic versus functional remission in patients with schizophrenia. Eur Psychiatry 27:401-405

2. Madhivanan S, Jayaraman K, Daniel S, Ramasamy J (2017) Symptomatic remission in schizophrenia and its relationship with functional outcome measures in Indian population. J Clin Diagn Res 11(1):VC05-VC07

3. Al Ageel B, Margolese H (2012) Remission in schizophrenia: critical and systematic review. Harv Rev Psychiatry 20(6):281-297

4. Emsley R, Chiliza B, Asmal L, Lehloenya K (2011) The concepts of remission and recovery in schizophrenia. Curr Opin Psychiatry 24(2):114-121

5. Johansson $M$, Hjärthag F, Helldin L (2020) Cognitive markers related to long-term remission status in schizophrenia spectrum disorders. Psychiatry Res 289:113035

6. Brissos S, Dias V, Balanzá-Martinez V, Carita A, Figueira M (2011) Symptomatic remission in schizophrenia patients: relationship with social functioning, quality of life, and neurocognitive performance. Schizophr Res 129:133-136

7. Andreasen N, Carpenter W, Kane J, Lasser R, Marder S, Weinberger D (2005) Remission in schizophrenia: proposed criteria and rationale for consensus. Am J Psychiatry 162:441-449
8. Bodén R, Sundström J, Lindström E, Lindström L (2009) Association between symptomatic remission and functional outcome in first-episode schizophrenia. Schizophr Res 107:232-237

9. Bobes J, Ciudad A, Álvarez E, San L, Polavieja P, Gilaberte I (2009) Recovery from schizophrenia: results from a 1-year follow-up observational study of patients in symptomatic remission. Schizophr Res 115(1):58-66

10. First MB, Spitzer RL, Gibbon M, Williams JBW (1997) Structured clinical interview for DSM-IV Clinical Version (SCID-I/CV). American Psychiatric Press, Washington, DC

11. El-Missiry A (2003) Homicide and psychiatric illness: an Egyptian study. Dissertation, Ain Shams University

12. Kay SR, Opler LA, Lindenmayer JP (1988) Reliability and validity of the positive and negative syndrome scale for schizophrenics. Psychiatry Res 23.99-110

13. Hall R (1995) Global assessment of functioning. A modified scale. Psychosomatics 36(3):267-275

14. Clifford P (1987) The social functioning questionnaire, vol 45. Research and Development for Psychiatry, London, pp 808-813

15. Hussein H, El-Shafei A, Okasha T (2006) Working with families of patients with schizophrenia: a rewarding alternative to classical community care in developing countries. Egypt J Psychiatr 25:11-17

16. Harrison G, Hopper K, Craig T, Laska E, Siegel C, Wanderling J, Dube KC, Ganev K, Giel R, an der Heiden W et al (2001) Recovery from psychotic illness: a 15- and 25-year international follow-up study. Br J Psychiatry 178:506-517

17. Menezes N, Arenovich T, Zipursky R (2006) A systematic review of longitudinal outcome studies of first-episode psychosis. Psychol Med 36(10):1349-1362

18. Bachmann S, Bottmer C, Schroder J (2008) One-year outcome and its prediction in first-episode schizophrenia-a naturalistic study. Psychopathology 41:115-123

19. IBM Corp (2012) IBM SPSS Statistics for Windows (Version 21.0). [Software]. IBM Corp, Armonk

20. Kurihara T, Kato M, Reverger R, Tirta I (2011) Remission in schizophrenia: a community-based 6-year follow-up study in Bali. Psychiatry Clin Neurosci 65:476-482

21. Brown A (2011) The environment and susceptibility to schizophrenia. Prog Neurobiol 93:23-58

22. Khan N, Kausar R, Khalid A, Farooq A (2015) Gender differences among discrimination \& stigma experienced by depressive patients in Pakistan. Pak J Med Sci 31(6):1432-1436

23. Lane A, Byrne M, Mulvany F, Kinsella A, Waddington JL, Walsh D, Larkin C, O'Callaghan E (1995) Reproductive behaviour in schizophrenia relative to other mental disorders: evidence for increased fertility in men despite reduced marital rate. Acta Psychiatr Scand 91:222-228

24. CAPMAS (2018) Economic census - Egypt 2018. https://www.capmas. gov.eg/Admin/Pages\%20Files/202041411564PART\%201\%20TKRIR.pdf. Accessed 8 Mar 2021

25. Drake R, Dunn G, Tarrier N, Bentall R, Haddock G, Lewis S (2007) Insight as a predictor of the outcome of first-episode non-affective psychosis in a prospective cohort study in England. J Clin Psychiatry 68:81-86

26. Mansour H, Fathi W, Klei L, Wood J, Chowdari K, Watson A, Eissa A, Elassy M, Ali I, Salah H et al (2000) Consanguinity and increased risk for schizophrenia in Egypt. Schizophr Res 120(1-3):108-112

27. Jaracz K, Górna K, Kiejda J, Grabowska-Fudala B, Jaracz J, Suwalska A Rybakowski JK (2015) Psychosocial functioning in relation to symptomatic remission: a longitudinal study of first episode schizophrenia. Eur Psychiatry 30:907-913

28. Emsley R, Oosthuizen P, Niehaus D, Koen L, Chiliza B (2007) Changing the course of schizophrenia-predictors of treatment outcome revisited. SAJP 13(1):4-9

29. Jana AK (2021) Clinical and sociodemographic associates of remission from positive symptoms in schizophrenia. East Asian Arch Psychiatry 31(1):13-18. https://doi.org/10.12809/eaap1961

30. Simonsen E, Friis S, Haahr U, Johannessen JO, Larsen TK, Melle I, Opjordsmoen S, Rund BR, Vaglum P, McGlashan T (2007) Clinical epidemiologic first-episode psychosis: 1-year outcome and predictors. Acta Psychiatr Scand 116:54-61

31. Helldin L, Kane J, Karilampi U, Norlander T, Archer T (2007) Remission in prognosis of functional outcome: a new dimension in the treatment of patients with psychotic disorders. Schizophr Res 93:160-168 
32. Barak Y, Aizenberg D (2012) Clinical and psychosocial remission in schizophrenia: correlations with antipsychotic treatment. BMC Psychiatry 12:108-112

33. Younes AA, Moselhy HF (2009) A nation under siege: the 15-year outcome of Iraqi patients with schizophrenia in Babylon, Iraq. J Ment Health 18(5):398-404

34. Lambert M, De Marinis T, Pfeil J, Naber D, Schreiner A (2010) Establishing remission and good clinical functioning in schizophrenia: predictors of best outcome with long-term risperidone long-acting injectable treatment. Eur Psychiatry 25:220-229

35. Üçok A, Gorwood P, Karadayı G (2012) Employment and its relationship with functionality and quality of life in patients with schizophrenia: EGOFORS Study. Eur Psychiatry 27(6):422-425
36. Immonen J, Jääskeläinen E, Korpela H, Miettunen J (2017) Age at onset and the outcomes of schizophrenia: a systematic review and meta-analysis. Early Interv Psychiatry 11(6):453-460

37. Higashi K, Medic G, Littlewood K, Diez T, Granström O, De Hert M (2013) Medication adherence in schizophrenia: factors influencing adherence and consequences of nonadherence, a systematic literature review. Ther Adv Psychopharmacol 3(4):200-218

\section{Publisher's Note}

Springer Nature remains neutral with regard to jurisdictional claims in published maps and institutional affiliations.

\section{Submit your manuscript to a SpringerOpen ${ }^{\circ}$ journal and benefit from:}

- Convenient online submission

- Rigorous peer review

- Open access: articles freely available online

- High visibility within the field

Retaining the copyright to your article

Submit your next manuscript at $\boldsymbol{\nabla}$ springeropen.com 